\title{
BLOOD PICTURE AND BIOCHEMICAL COMPOSITION OF THE BLOOD IN SOWS BETWEEN WEANING AND SUBSEQUENT ESTRUS
}

\author{
A. HLOUŠEK, E. KUDLÁC̆, JARMILA NEDBÁLKOVÁ, B. STUDENČíK \\ AND RƯŽENA SVOBODOVÁ \\ Department of Reproduction of Farm Animals and Surgery, University \\ of Veterinary Science, 61242 Brno
}

Received Fuly 22, 1982

\begin{abstract}
Hloušek A., E. Kudláč, Jarmila Nedbálková, B. Studenčík, Rủžena Svobodová: Blood Picture and Biochemical Composition of the Blood in Sows between Weaning and Subsequent Estrus. Acta vet. Brno, 53, 1984: 57-63.

The blood picture and biochemical composition of the blood in 79 sows between weaning and subsequent estrus was investigated and compared with the values obtained in 39 lactating sows. The mean erythrocyte counts were higher after weaning $\left(5.9 \pm 0.6 \cdot 10^{12} / 1\right)$ than in lactating sows $\left(5.7 \pm 0.8 \cdot 10^{12} / 1\right)$. The highest erythrocyte counts were observed during estrus $\left(6.7 \pm 0.4 .10^{12} / 1\right)$. The hemoglobin concentration ranged between 11 and $13 \mathrm{~g} / \mathrm{dl}$. The highest hematocrit value was found on day 10 after weaning $(0.40 \pm 0.07)$. The highest erythrocyte sedimentation rate was found on the day of weaning. The total protein concentration was higher in lactating sows $(78.4 \pm 7.1 \mathrm{~g} / 1)$ than in those after weaning $(69.2$ to $75.2 \mathrm{~g} / \mathrm{l})$. The mean leukocyte counts increased after weaning up to $16.460 \pm 3150$. The neutrophil counts were high in the first days after weaning (53.7 per cent), the lymphocyte counts increased within a week after weaning to 48.3 per cent.

The plasma $\mathrm{Ca}$ concentration increased from $2.21 \pm 0.41 \mathrm{mmol} / 1$ to $2.60 \pm 0.24$ mmol|l. The plasma glucose concentration ranged between $3.36 \pm 0.62$ and $5.63 \pm$ $\pm 0.86 \mathrm{mmol} / 1$; the lower value was found on the day of weaning. The vitamin $\vec{A}$ concentration was lowest during lactation $(232.5 \pm 82.0 \mathrm{mg} / \mathrm{l})$. The enzyme activities were rather unstable and changed in wide limits (acid phosphatase from 69.6 to $151.6 \mathrm{~kat} / \mathrm{l}$, alkaline phosphatase from 0.205 to $0.483 \mathrm{~kat} / \mathrm{l}, \mathrm{LDH}$ from 157.3 to 240.1 $\mathrm{kat} / \mathrm{l}, \mathrm{GOT}$ from 0.117 to $0.374 \mathrm{~kat} / \mathrm{l}$, GPT from 0.142 to $0.357 \mathrm{~kat} / \mathrm{l}$ ).
\end{abstract}

Sow, weaning, estrus, blood, vitamins, enzymes, glucose.

Morphological and biochemical composition of the blood is affected by numerous factors of the internal and external environment. One of such factors is the reproductive process. Information about the health state of the sows before gestation based on laboratory examination may provide data useful for improvement of fertilization and natality of the offspring.

Morphology and biochemistry of the blood in sows has been described in detail by many authors (Wirth 1952; Schalm 1961; Kudrjavcev and Kudrjavceva 1972; Maclean 1972; Nachreiner et al. 1972; Gabriš 1975; Herak et al. 1975; Bostedt 1978 and others). The majority of available data provide information on changes in sows during pregnancy, parturition and puerperium but we found no data on blood morphology and biochemistry in sows in the period between weaning and the subsequent estrus.

The aim of this work was therefore to study the morphological and biochemical parameters of the sow's blood in the above-mentioned period. On our earlier studies, these parameters have been described in gills (Hloušek 1978), in sows during pregnancy and puerperium (Hloušek 1979; Kudláč et al. 1980). The present study was carried out in the same enterprise and under the same experimental conditions as the above-mentioned work. 


\section{Materials and Methods}

Morphological and biochemical composition of the blood was investigated in 79 sows of the Large White breed and Large White $\times$ Přeštické cross, 1 to 3 years old in the period between weaning and the subsequent estrus. The results were compared to those obtained in 39 lactating sows of the same breeds and age. The animals were divided in groups as follows:

I. group of 39 lactating sows

II. group of 15 sows, on the day of weaning of piglets

III. group of 16 sows, 3 days after weaning

IV. group of 16 sows, 5 days after weaning

V. group of 18 sows, 7 days after weaning

VI. group of 14 sows, 10 and more days after weaning and showing no signs of estrus as yet.

The sows were kept under usual large-scale conditions in windowless houses and fed a standard diet for sows with free access to drinking water. The animals were also offered whey. The majority of sows showed estrus signs between days 5 and 7 after their piglets had been weaned.

Blood samples were collected from the ear vein and immediately processed for morphological and biochemical examinations by conventional methods (see Hořejši 1964, 1970) in our laboratory. For statistical evaluation of the results Student's t-test was employed.

\section{Results}

Blood picture of sows between weaning and subsequent estrus

The results are presented in Tables 1 to 4 . They indicate a significant increase in erythrocyte count within 3 and 7 days after weaning, i. e. at the time of most frequent estrus occurrence. The only exception was the Group IV, i. e. the sows 5 days after weaning whose erythrocyte counts slightly declined.

Small differences ocured in the hemoglobin concentration. It was highest in Group VI., lowest in Group V.

Hematocrit rose more in sows showing signs of estrus (Group VI) in others no significant differences were detected.

Erythrocyte sedimentation rate (ESR) (1 and 2 hours) was most rapid in Group II on the day of weaning, ESR after $24 \mathrm{~h}$ was most rapid in Groups V. and II.

Total protein amount in the blood serum was lower at weaning in all groups of sows than during lactation. In Groups IV. and V. significant differences were found.

The WBC count increased in sows after their offspring had been weaned and it was not until day 7 that it decreased again. The differences, however, were not significant in majority of cases.

The neutrophil: lymphocyte ratio underwent rather interesting changes. The neutrophil granulocyte count remained relatively high in the first days after weaning (rods $1.7 \pm 0.8 \%$, segments $52.0 \pm 5.3 \%$ ) and it was only after day 7 post weaning that these cells decreased in numbers (rods $1.4 \pm 0.6 \%$, segments $40.5 \pm 7.8 \%$ ). The lymphocyte count increased significantly in Groups $\mathrm{V}$ and VI.

Biochemical parameters of the blood in sows between weaning and subsequent estrus

The results including their statistical evaluation are presented in Tables 3 and 4.

The plasma Ca concentration increased after weaning of piglets but decreased 


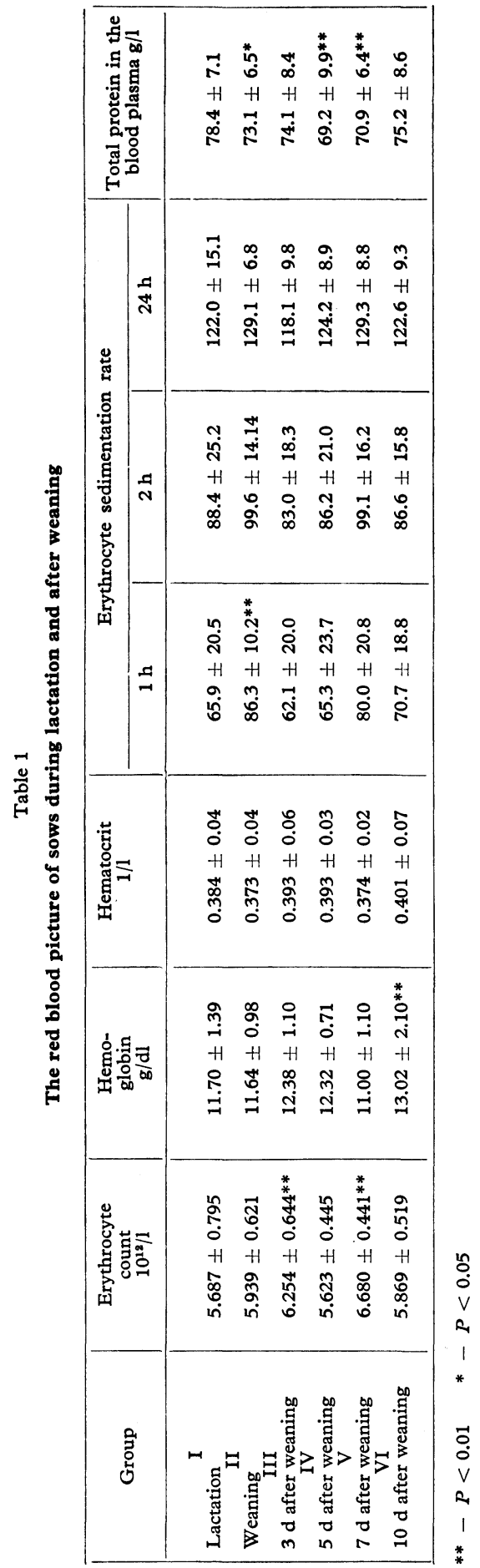


Table 2

The white blood picture of sows during lactation and after weaning

\begin{tabular}{|c|c|c|c|c|c|c|c|}
\hline Group & $\begin{array}{c}\text { Leukocytes } \\
10^{9} / 1\end{array}$ & $\mathrm{Ba} \%$ & Eo \% & $\operatorname{Rod} \%$ & Seg. \% & Ly \% & Mo \% \\
\hline $\begin{array}{l}\text { I } \\
\text { Lactation } \\
\text { II } \\
\text { Weaning } \\
\text { III } \\
3 \mathrm{~d} \text { after weaning } \\
\text { IV } \\
5 \mathrm{~d} \text { after weaning } \\
\text { V } \\
7 \mathrm{~d} \text { after weaning } \\
\text { VI } \\
10 \mathrm{~d} \text { after weaning }\end{array}$ & $\begin{array}{l}13.29 \pm 4.53 \\
13.95 \pm 2.98 \\
13.41 \pm 4.98 \\
16.46 \pm 3.15^{*} \\
11.41 \pm 2.23 \\
10.68 \pm 3.01\end{array}$ & $\begin{array}{l}0.6 \pm 0.3 \\
0.6 \pm 0.6 \\
0.6 \pm 0.4 \\
0.8 \pm 0.7 \\
0.7 \pm 0.5 \\
0.5 \pm 0.3\end{array}$ & $\begin{array}{l}5.1 \pm 3.3 \\
3.6 \pm 2.1 * \\
5.9 \pm 4.0 \\
4.9 \pm 1.8 \\
6.5 \pm 3.1 \\
3.4 \pm 1,8^{* *}\end{array}$ & $\begin{array}{l}2.2 \pm 1.0 \\
1.7 \pm 0.8 \\
1.7 \pm 0.8 \\
2.1 \pm 0.8 \\
1.4 \pm 0.6^{*} \\
1.3 \pm 0.7^{*}\end{array}$ & $\begin{array}{l}46.9 \pm 7.9 \\
52.0 \pm 5.3^{*} \\
43.9 \pm 8.5 \\
47.3 \pm 5.3 \\
40.5 \pm 7.8^{* *} \\
40.2 \pm 5.2^{* *}\end{array}$ & $\begin{array}{l}43.4 \pm 6.4 \\
40.3 \pm 6.2 \\
46.0 \pm 8.8 \\
42.9 \pm 6.1 \\
48.3 \pm 7.1^{*} \\
52.0 \pm 10^{* *}\end{array}$ & $\begin{array}{l}1.8 \pm 0.9 \\
1.8 \pm 2.0 \\
1.9 \pm 1.5 \\
2.0 \pm 1.6 \\
2.6 \pm 2.4^{* *} \\
2.6 \pm 1.0^{* *}\end{array}$ \\
\hline
\end{tabular}

** $P<0.01$

$* P<0.05$

Table 3

Chemical composition of the blood in sows during lactation and after weaning

\begin{tabular}{|c|c|c|c|c|c|c|}
\hline Group & $\underset{\mathrm{mmol} / 1}{\mathrm{Ca}}$ & $\underset{\mathrm{mmol} / 1}{\mathbf{P}}$ & $\underset{\mathrm{mmol} / \mathrm{l}}{\mathrm{Mg}}$ & $\begin{array}{l}\text { Glucose } \\
\mathrm{mmol} / 1\end{array}$ & $\begin{array}{l}\text { Bilirubin } \\
\mathrm{mmol} / 1\end{array}$ & $\begin{array}{c}\text { Cholesterol } \\
\mathrm{mmol} / 1\end{array}$ \\
\hline I & & & & & & \\
\hline $\begin{array}{l}\text { Lactation } \\
\text { II }\end{array}$ & $2.21 \pm 0.41$ & $1.50 \pm 0.16$ & $0.759 \pm 0.127$ & $5.10 \pm 0.95$ & $4.79 \pm 2.05$ & $2.81 \pm 0.42$ \\
\hline $\begin{array}{l}\text { Weaning } \\
\text { III }\end{array}$ & $2.24 \pm 0.52$ & $1.31 \pm 0.14^{* *}$ & $0.668 \pm 0.110$ & $3.36 \pm 0.62 * *$ & $7.01 \pm 0.96^{* *}$ & $2.41 \pm 0.38^{* *}$ \\
\hline $\begin{array}{l}3 \mathrm{~d} \text { after } \\
\text { weaning } \\
\text { IV }\end{array}$ & $2.60 \pm 0.24$ & $1.41 \pm 0.16$ & $0.648 \pm 0.103^{*}$ & $5.63 \pm 0.86$ & $6.67 \pm 2.74^{* *}$ & $2.45 \pm 0.39 * *$ \\
\hline $\begin{array}{l}5 \mathrm{~d} \text { after } \\
\text { weaning } \\
\mathrm{V}\end{array}$ & $2.41 \pm 0.44$ & $1.34 \pm 0.21^{*}$ & $0.668 \pm 0.172 *$ & $4.91 \pm 0.93$ & $3.93 \pm 1.47$ & $3.33 \pm 0.51^{* *}$ \\
\hline $\begin{array}{l}7 \mathrm{~d} \text { after } \\
\text { weaning } \\
\text { VI }\end{array}$ & $2.24 \pm 0.48$ & $1.47 \pm 0.27$ & $0.726 \pm 0.189$ & $4.38 \pm 0.92^{*}$ & $5.47 \pm 1.83$ & $2.42 \pm 0.49 * *$ \\
\hline $\begin{array}{l}10 \mathrm{~d} \text { after } \\
\text { weaning }\end{array}$ & $2.12 \pm 0.52$ & $1.79 \pm 0.27^{* *}$ & $0.828 \pm 0.094$ & $5.10 \pm 0.013$ & $5.64 \pm 0.17$ & $2.26 \pm 0.21 * *$ \\
\hline
\end{tabular}

** $P<0.01$

$* P<0.05$

Table 4

The vitamin A concentration and activities of plasma enzymes in sows during lactation and after weaning

\begin{tabular}{|c|c|c|c|c|c|c|}
\hline \multirow[b]{2}{*}{ Group } & \multirow{2}{*}{$\underset{\mathrm{mg} / 1}{\operatorname{Vitamin} \mathrm{A}}$} & \multirow{2}{*}{$\begin{array}{c}\text { Alkaline } \\
\text { phosphatase } \\
\text { kat } / 1\end{array}$} & \multirow{2}{*}{$\begin{array}{c}\text { Acid } \\
\text { phosphatase } \\
\text { n kat/1 }\end{array}$} & \multicolumn{3}{|c|}{ Enzymes } \\
\hline & & & & $\begin{array}{l}\text { LDH } \\
\text { IU }\end{array}$ & $\begin{array}{l}\text { GOT } \\
\mathrm{kat} / 1\end{array}$ & $\begin{array}{l}\text { GPT } \\
\text { kat/1 }\end{array}$ \\
\hline & $232.5 \pm 82.0$ & $0.343+0.167$ & $140.4+51.9$ & $1573+43.6$ & $0.234+0.073$ & $0.240+$ \\
\hline II & $232.0 \pm 02.0$ & $0.040 \pm 0.101$ & $140.4 \pm 21.9$ & $101.0 \pm 43.0$ & $0.234 \pm 0.013$ & $0.240 \pm 0.004$ \\
\hline Weaning & $477.8 \pm 113.4^{* *}$ & $0.205 \pm 0.113^{*}$ & $128,9 \pm 38.6$ & $194.1 \pm 26.9 *$ & $0.117 \pm 0.053^{* *}$ & $0.306 \pm 0.092$ \\
\hline $\begin{array}{l}3 \mathrm{~d} \text { after } \\
\text { weaning } \\
\text { IV }\end{array}$ & $317.8 \pm 79.3^{*}$ & $0.401 \pm 0.264$ & $69.6 \pm 47.6 * *$ & $180.2 \pm 58.7$ & $0.229 \pm 0.053$ & $0.441 \pm 0.081 * *$ \\
\hline $\begin{array}{l}5 \mathrm{~d} \text { after } \\
\text { weaning } \\
\mathrm{V}\end{array}$ & $245.1 \pm 73.0$ & $0.483 \pm 0.231 *$ & $105.4 \pm 80.2$ & $192.0 \pm 49.1^{*}$ & - & - \\
\hline $\begin{array}{l}7 \mathrm{~d} \text { after } \\
\text { weaning } \\
\text { VI }\end{array}$ & $269.6 \pm 158.6$ & $0.474 \pm 0.211^{*}$ & $151.6 \pm 85.3$ & $177.1 \pm 28.8$ & $0.229 \pm 0.098$ & $0.357 \pm 0.131 * *$ \\
\hline $\begin{array}{l}10 \mathrm{~d} \text { after } \\
\text { weaning }\end{array}$ & $297.4 \pm 86.6$ & $0.338 \pm 0.169$ & $90.3 \pm 35.1 *$ & $240.1 \pm 28.8^{* *}$ & $0.374 \pm 0.116^{* *}$ & $0.142 \pm 0.095^{* *}$ \\
\hline
\end{tabular}

** $P<0.01$

$* P<0.05$ 
again within the following week. The differences were not significant. The highest $P$ values were found in Groups $\mathrm{I}, \mathrm{V}$ and VI. The $\mathrm{Mg}$ concentration showed no conspicuous changes.

The plasma glucose concentration ranged between $3.36 \pm 0.62$ and $5.63 \pm$ $\pm 0,93 \mathrm{mmol} / \mathrm{l}^{-1}$. It decreased significantly on the day of weaning.

The highest bilirubin concentration was found on the day of weaning the piglets $\left(7.01 \pm 0.96 \mathrm{mmol} / \mathrm{1}^{-1}\right)$ decreasing abruptly within the following 5 days (3.93 \pm $\left.\pm 1.47 \mathrm{mmol} / \mathrm{l}^{-1}\right)$.

Cholesterol concentration reached a maximum on day 5 after weaning $(3.33 \pm$ $\pm 0.51 \mathrm{mmol} / 1)$, declined thereafter to $2.26 \pm 0.21 \mathrm{mmol} / 1$ on day 10 .

The vitamin A concentration was lowest during lactation.

Activities of the plasma enzymes under study oscillated considerably without showing any distinct trends: alkaline phosphatase between 0.205 and $0.483 \mathrm{~kat} / \mathrm{l}$, acid phosphatase between 69.6 and $151.5 \mathrm{~m}$ kat/1. LDH between 157.3 and 240.1 kat/l, GOT between 0.117 and $0.374 \mathrm{~kat} / \mathrm{l}, \mathrm{GPT}$ between 0.142 and $0.357 \mathrm{~kat} / \mathrm{l}$. Only LDH showed a somewhat higher activity in all groups as against Group I.

\section{Discussion}

Many aspects of morphology and biochemistry of blood in sows have been studied including the effects of various phases of the reproduction cycle. No data have been available so far on blood characteristics in sows in the interval between weaning their offspring and the onset of subsequent estrus. Due to changes such as cessation of lactation and new proestrus and estrus certain reflections in the blood picture may be expected. The changes in endocrine profile, especially the increasing estrogen concentration results in changes of both morphological and biochemical blood composition of sows (Rožek and Brixe 1971). However, only slight changes have been found in both RBC and WBC counts in sows during puerperium (Kudláč 1976).

Weaning of the piglets caused no significant changes in the RBC. The observed increase in $\mathrm{RBC}$ and $\mathrm{Hb}$ concentration on days 5 and 7 is connected with the onset of estrus as shown also by Rožek and Brixe (1971). A transient increase in the numbers of eosinophils and decrease of segmented neutrophils may also be due to estrus. The biochemical parameters of the blood plasma of sows on the day of weaning as compared to the lactating ones shows significant changes that are, no doubt, due to weaning and a one day fast. Repeatedly higher vitamin A concentrations observed in our experimental animals may lie in its lower secretion in milk of these sows.

Our findings cannot be interpreted as a direct results of the changed endocrinological profile connected with an early onset of estrus after weaning.

In conclusion, the observed changes in blood composition of sows during the post-weaning period, even if some of them were significant, cannot be employed for detection of phases of the reproductive cycle although a long-time study of this question may provide some basic data. 


\section{Morfologický obraz a biochemická skladba krve prasnic v období od odstavu selat do říje}

Morfologický obraz a biochemická skladba krve byla sledována u 79 prasnic $\mathrm{v}$ době od odstavu selat do ř́ije a u 39 prasnic v období laktace. Průměrné počty erytrocytů byly vyšší po odstavu $\left(5,9 \pm 0,6.10^{12} / 1\right)$ než v období laktace $(5.7 \pm$ $\left.\pm 0.8 .10^{12} / 1\right)$, nejvyšší počet byl u prasnic $\mathrm{v}$ období ř́je, tj. $6.7 \pm 0.4 .10^{12} / 1$. Obsah hemoglobinu se pohyboval kolem $11-13 \mathrm{~g} / \mathrm{dl}$. Hematokrit byl nejvyší za 10 dní po odstavu selat $0.4 \pm 0.071 / 1$. Sedimentace byla nejrychlejší u krve odebrané od prasnic $\mathrm{v}$ den odstavu. Obsah celkových bílkovin byl vyšší $\mathrm{v}$ období laktace $(78.4 \pm 7.1 \mathrm{~g} / \mathrm{l})$ než po odstavu (od 69.2 do $75.2 \mathrm{~g} / 1$ ). Prưměrné počty leukocytů se zvyšovaly po odstavu až na $16460 \pm 3150$. Podíl neutrofilù byl vysoký v prvých dnech po odstavu selat $(53.7 \%$ ), podíl lymfocytů se zvýšil za týden po odstavu selat na $48.3 \%$.

Obsah Ca se po odstavu zvyšoval z $2.21 \pm 0.41 \mathrm{mmol} / 1$ až na $2.6 \pm 0.24 \mathrm{mmol} / 1$. Koncentrace glukózy kolísala mezi $3.36 \pm 0.62$ a $5.63 \pm 0.24 \mathrm{mmol} / 1$. Nejnižší její koncentrace byla nalezena $\mathrm{v}$ den odstavu selat. Obsah vitamínu A byl nejnižší v údobí laktace $(232.5 \pm 82.0 \mathrm{mg} / \mathrm{l})$. Aktivita sledovaných enzymů kolísala značně a bez př́mé závislosti na údobí sledovaného reprodukčního cyklu.

\section{Морфологическая картина и биохимическая структура крови свиноматок в период от отлучения приплода до течки}

Морфологическая картина и биохимическая структура крови были исследованы у 79 свиноматок от отлучения приплода до течки и у 39 свиноматок в период лактации. Среднее число эритроцитов было выше после отлучения $\left(5,9 \pm 0,6.10^{12} / 1\right)$ чем в период лактации $\left(5,7 \pm 0,8.10^{12} / 1\right)$, самое большое число было установлено у свиноматок в период течки - т. е. $6,680000 \pm$ 0,441. Содержание гемоглобина колебалось около 11-13 г/дл. Самая максимальная величина гематокрита была определена через 10 суток после отлучения приплода $-0,40 \pm 0,7$ л/л. Самая быстрая седиментация наблюдалась у крови свиноматок в день отлучения. Содержание общих белков было максимальным в период лактации $(78,4 \pm 7,1$ г/л) чем после отлучения (от 69,2 до 75,2 г/л). Среднее число лейкоцитов увеличивалось после отлучения до $16460 \pm 3150$. Доля нейтрофилей была высокая в первые дни после отлучения поросят $(53,7 \%)$, доля лимфоцитов увеличилась через неделю после отлучения поросят до $48,3 \%$.

Содержание кальция после отлучения увеличивалось из $2,21 \pm 0,41$ ммоль/л до 2,60 $\pm 0,24$ ммоль/л. Уровень сахара колебался с пределах $3,36 \pm 0,65$ ммол/л до 5,63 $\pm 0,86$ ммоль/л, нижний предел был установлен в день отлучения. Содержание витамина А было минимальным в период лактации $-232,5 \pm 82,00$ мг/л. Активность исследуемых энзимов колебалась значительно и без прямой зависимости: К - от 69,6 до 151,6 кат./л, А - 0,205-0,483 кат./л, LOH - 157,3-240,1 кат./л, GOT - 0,117-0,374 кат./л, GPT - 0,1^2-0,357 кат./л. 


\section{References}

BOSTEDT, H.: Das Schwein in der ante- und postpartalen Periode. 1. Mitt., Berl. Münch. T. Wchschr., 91, 1978: $21-24$.

BOSTEDT, H.: Das Schwein in der ante- und postpartalen Periode. 2. Mitt., Berl. Münch. T. Wchschr., 91, 1978: 51-53.

GABRIS, J.: Vztah medzi počtom leukocytov a neutrofilných granulocytov u prasníc pred pôrodom, pri pôrode a počas dojčenia. Folia veter., 19, 1975: 151-161.

HERAK, M. - HERAK, M. - SOJAK, Z.: Promjenje kolicine ukupnih bjeljanceva u krvnom serunu krmaca u toku graviditeta, laktacije i nakon odbijanja prasadi. Vet. Arh., 45, 1975: 49-56.

HERAK, M. - HERAK, M. - KOVAČEVIČ, V. - ŠIMUNDIČ, B. - BENDIČ-RISTIC, G.: Promjenje aktivnosti tranzaminaza, te alkalne, kisele fosfataze u krvnom serumu krmača za vrijeme laktaciji i poslije odbijanja prasadi. Vet. Arh., 45, 1975: 71-82.

HLOUŠEK, A.: Age-dependent changes in blood count of gilts in large-scale piggeries. Acta Vet. Brno, 47, 1978: 7-13.

HLOUŠEK, A.: Age dependent changes in biological composition of blood in gilts from large-scale piggeries. Acta vet. Brno, 47, 1978: 15-21.

HLOUŠEK, A.: Změny v krevním obrazu během březosti u prasnic plemene bílé ušlechtilé, chovaných ve velkovýrobních podmínkách. Vet. Med. Praha, 24, 1979: 455-464.

HLOUŠEK, A.: Změny $\mathrm{v}$ biochemickém složení krve během březosti u prasnic plemene bílé ušlechtilé, chovaných ve velkovýrobních podmínkách. Vet. Med. Praha. 24, 1979; 65-473.

HLOUŠEK, A. - KUDLÁČ, E. - STUDENČfK, B. - SVOBODOVÁ, R. - NEDBÁLKOVÁ, J.: Morfologické a biochemické změny v krvi prasnic během některých etap reprodukčního cyklu. Reprodukcia hospodárskych zvierat. Zborník referátov V. Přibylove dni, Košice 1981, pp. $51-53$.

HOŘEJŠf, J. - FASSATI, M. - JfCHA, J. - KANDRÁČ, M. - MAŠEK, K. - MICHALEC, Č. - SLAVIK, K.: Základy chemického vyšetřování v lékařství. SZN, Praha 1964, 696.

HOŘEJŠf́, J.: Základy klinické biochemie ve vnitřním lékařství. SZN, Praha 1970, 548.

KUDLÁČ, E.: Změny v krevním obraze během puerperia u prasnic českého bílého plemene chovaných ve velkovýrobních podmínkách. Vet. medicína, 21, 1976: 265-272.

KUDLÁĆ, E. - HRIVNÁK, J. - NEDBÁLKOVÁ, J. - STUDENČfK, B.: Hladina některých minerálií, glukózy a vitamínu A v krevním séru prasnic během puerperia v podmínkách velkochovu. Vet. medicína, 21, 1976: 257-263.

KUDLÁC, E. a kol.: Rozmnožovací schopnosti prasnic a ovlivňování jejich reprodukce. Project. report, University of Veterinary science, Brno 1980, 41.

KUDRJAVCEV, A. A. - KUDRJAVCEVA, L. A.: Kliničeskaja gematologia životnych. Kolos, Moskva 1974, 399.

NACHREINER, R. F. - GINTHER, O. J.: Gestational and periparturient period of sows: serum chemical, haematologic, and clinical changes during the periparturient period. Amer. J. vet. Res., 33, 1972, 2233-2238.

NACHREINER, R. F. - GARCIA, M. C. - GINTHER, O. J.: Clinical, haematologic and blood chemical changes in swine during immediate postpartum period. Am. J. vet. Res., 33, 1972: $2489-2499$.

ROTH, Z. - JOSfFFKO, M. - MALÝ, V. - TRČKA, V.: Statistické metody v experimentální medicíně. SZN, Praha 1962, 592.

ROŽEK, J. - BRIXA, J.: Změny v krevním obrazu a obsahu některých minerálií a fermentů v krvi prasnic v průběhu pohlavního cyklu. Referát na SVK, VŠV, Brno 1971.

SCHALM, N. C. - CAROLI, E. J.: Veterinary haematology. Lea and Febiger, Philadephia, $1975,807$.

WIRTH, D.: Grundlagen einer klinischen Hämatologie der Haustiere. Urban u. Schwarzenberg, Wien u. Innsbruck 1950, 372. 